\title{
A Study of the Effect of Fiber Content and Fiber Orientation on the Tensile Strength of Glass Fiber Reinforced Epoxy Composite for Pipe Production: A Taguchi and Statistical Approach
}

Bassey Okon Samuel ( $\nabla$ basseyokon59@gmail.com )

Ahmadu Bello University https://orcid.org/0000-0001-9104-7063

Danjuma Saleh Yawas

Ahmadu Bello University

Imaobong Okpongette Akpan

Federal Polytechnic

\section{Research Article}

Keywords: Composites, Natural Fibers, Optimization, Taguchi

Posted Date: January 27th, 2022

DOI: https://doi.org/10.21203/rs.3.rs-1284793/v1

License: (c) (i) This work is licensed under a Creative Commons Attribution 4.0 International License.

Read Full License 


\title{
A Study of the Effect of Fiber Content and Fiber Orientation on the Tensile Strength of Glass fiber Reinforced Epoxy Composite for Pipe Production: A Taguchi and Statistical Approach
}

\author{
Authors: \\ Bassey Okon SAMUEL, * \\ Mechanical Engineering, Ahmadu Bello University, Zaria \\ basseyokon59@gmail.com \\ Danjuma Saleh YAWAS, \\ Mechanical Engineering, Ahmadu Bello University, Zaria \\ dsyawas@abu.edu.ng \\ Imaobong Okpongette AKPAN, \\ Mechanical Engineering, Federal Polytechnic, Ukana. \\ imaobongokpongette@gmail.com \\ *Corresponding Author
}

\begin{abstract}
This study was aimed at optimizing the development parameters of a glass fiber reinforced epoxy composite for pipeline application. In this study, the Taguchi experimental design technique was applied to determine the best combination of process parameters (fiber content and orientation) for optimum tensile strength. The optimum tensile strength of $209.65 \mathrm{MPa}$ was reported at the fiber content of $50 \%$ and Fiber orientation of $45^{\circ}$. Analysis of variance also showed that in optimizing for high tensile strength, the glass fiber content and the fiber orientation are significant factors. The material at optimum tensile properties was applied in the simulation of the behavior of a high-pressured gas pipeline and results proved the reliability of the material in such application.
\end{abstract}

Keywords: Composites, Natural Fibers, Optimization, Taguchi 


\section{Introduction}

Pipeline increasingly found application in diverse industries worldwide due to their low-cost transportation of strategic fluids. In the development of pipelines for the transportation of various industrial fluids like water, acids, gases, oil, etc., fiber-reinforced polymer composites have been used due to their excellent properties like high strength, low density, corrosion resistance, etc. Also, the installation cost of these forms of composite pipes has been reduced due to technological development. With good mechanical strength, durability, pressure capacity, low cost, these fiber reinforced polymer composites (FRP) can be combined with other materials to achieve a good environmental footprint.

Metallic and composite pipes have been the most economic means of transportation of oil and gas and since metallic pipes are susceptible to corrosion, the FRPs have an advantage. With good mechanical, insulating, and deterioration resistance, glass fibers are economical and the most popularly used reinforcements in the development of polymerbased pipes. The most popular among these glass fiber reinforced polymer composites are the thermoset resin-based composites while the thermoplastic-based reinforced polymer composites are rarely applied in the development of pipes. Even for pipeline repairs, these thermosets can easily form on walls and harden quickly and they are also deterioration resistant. This gives them an advantage over thermoplastics in piping development. Some of these thermosets that are used in piping applications are polyesters, vinyl esters, phenolic, polyurethane, epoxy, polyamide, etc. Epoxy stands as the most popular in the development of glass fiber reinforced polymer composites for piping application due to its good mechanical properties, adhesion, chemical corrosion resistance, shrinkage, cure properties

Many studies on the behavior of glass fiber reinforced composites in various applications have been carried out. According to Joseph et al. (2002), composite development factors and parameters affects the mechanical strength, failure mode, fracture toughness, and modulus of fiber-reinforced composites. Some of these parameters include the volume fraction and angular orientation of the fiber. But, the interfacial parameters are of significance.

Mostafa et al. (2019) developed a jute/glass fiber hybrid reinforced epoxy composite and studied the effect of hybridization using tensile experiments. The hybridization resulted in a reduction in the tensile strength of the materials even though it increased the possibility of applying these agro-residues for composite material development. This implies that hybridization of the glass fiber reinforced particles with natural fibers is not advantageous to the mechanical property of the material as results prove lower performance when compared to composites reinforced with purely glass fibers. To improve the mechanical properties of these glass fiber reinforced polymer composites, other factors like the fiber orientation are more likely to be of significant and positive effect on the mechanical properties of these materials other than hybridization with natural fibers.

Elkazaz et al. (2020) investigated the effect of development parameters such as fiber length and volume fraction on the mechanical properties of short fiber reinforced polymer composites. An increase in fiber loading at a constant fiber length of $10 \mathrm{~mm}$ was more effective in increasing the strength and modulus of the material than increasing the fiber loading at a constant length of $5 \mathrm{~mm}$. Increasing tensile strength and modulus was also reported by Aramide et al. (2012) in a study that investigated the mechanical properties of woven mat fiberglass as reinforcement in polyester resin at a fiber loading of 5-30\%.

Many studies have detailed the excellent properties of glass fiber reinforced composites, but none have studied the combined effect of varied fiber content and orientation on the performance of such composites in high pressured pipeline production. This study will take advantage of the robust nature of the Taguchi design technique to optimize the tensile behavior of a glass fiber reinforced epoxy composite with varied fiber orientation. This will be achieved by considering the tensile strength based on the higher the better signal to noise ration criteria which is expressed in Equation 1.

$$
\left(\frac{S}{N}\right)_{H T B}=-10 * \log _{10}\left(\frac{1}{n} \sum_{i=1}^{n} \frac{1}{y_{i}^{2}}\right)
$$

Where $\mathrm{S} / \mathrm{N}$ is the signal to noise ratio, HTB represents "higher the better", $\mathrm{n}$ is the number of runs (combination) and $y_{\mathrm{i}}$ are tensile observations for each run. 


\section{Experimentation}

\section{Design of Experiment}

In this study, two factors (glass fiber content and orientation) will be optimized through five levels. Table 1 shows the different factors and their levels considered.

Table 1: Development factors and the levels of observation

\begin{tabular}{cccccc}
\hline $\begin{array}{c}\text { Factors } \\
\text { (Parameters) }\end{array}$ & $\mathbf{1}$ & $\mathbf{2}$ & Levels & \\
\hline \begin{tabular}{c} 
Fiber \\
\cline { 2 - 5 } Composition wt.
\end{tabular} & 10 & 20 & $\mathbf{3}$ & $\mathbf{4}$ & $\mathbf{5}$ \\
$\quad \begin{array}{c}\text { (\%) (A) } \\
\text { Fiber }\end{array}$ & & 30 & 40 & 50 \\
$\begin{array}{c}\text { Orientation }\left({ }^{\circ}\right) \\
(\mathrm{B})\end{array}$ & 0 & 15 & 30 & 45 & 60 \\
\hline
\end{tabular}

Using the Minitab 2018 software, an orthogonal array that detailed the combination of the factors at their various levels was developed. Since the number of factors considered was only two, a full factorial combination was observed. This is shown in Table 2.

Table 2: Orthogonal array for factors and level combination

\begin{tabular}{|c|c|c|}
\hline $\mathbf{S} / \mathbf{N}$ & Glass fiber content $(\%)$ & Glass fiber Orientation $\left(^{\circ}\right)$ \\
\hline 1 & 10 & 0 \\
\hline 2 & 10 & 15 \\
\hline 3 & 10 & 30 \\
\hline 4 & 10 & 45 \\
\hline 5 & 10 & 60 \\
\hline 6 & 20 & 0 \\
\hline 7 & 20 & 15 \\
\hline 8 & 20 & 30 \\
\hline 9 & 20 & 45 \\
\hline 10 & 20 & 60 \\
\hline 11 & 30 & 0 \\
\hline 12 & 30 & 15 \\
\hline 13 & 30 & 30 \\
\hline 14 & 30 & 45 \\
\hline 15 & 30 & 60 \\
\hline 16 & 40 & 0 \\
\hline 17 & 40 & 15 \\
\hline 18 & 40 & 30 \\
\hline 19 & 40 & 45 \\
\hline 20 & 40 & 60 \\
\hline 21 & 50 & 0 \\
\hline 22 & 50 & 15 \\
\hline 23 & 50 & 30 \\
\hline 24 & 50 & 45 \\
\hline 25 & 50 & 60 \\
\hline
\end{tabular}

\section{Composite development}

The hand-lay-up technique was used to produce the composites in line with the procedures of Batu et al., (2020) and Negawo et al., (2021) wherewith the concept of fiber orientation was also adopted. The epoxy resin and hardener 
were mixed in the ratio of 5:2 according to the manufacturer's specifications. The composite production was carried out at room temperature. The glass fiber strands were laid in the $3 \mathrm{~mm}$ thick mold according to their various specified orientation and the mixed resin and hardeners were poured into the mold and allowed to cure at room temperature. This method was used to produce the nine different combinations as specified in the orthogonal array presented in Table 2.

\section{Tensile Test}

Tensile tests on the specimens produced were carried out according to ASTM D638 using a Universal Testing Machine (INSTRON-3369). The specimen for the tensile test were cut from the prepared specimen and 3 tests each were carried out on the combinations.

\section{Results and Discussion}

Table 3 presents the mean and $\mathrm{S} / \mathrm{N}$ ratio of the tensile test carried out. The general mean of means of the different combinations or runs was $79.26 \mathrm{MPa}$ and the average $\mathrm{S} / \mathrm{N}$ ratio was 35.713 . Also, Table 4 presents the response table for means and $\mathrm{S} / \mathrm{N}$ ratio. The response table was obtained by averaging the levels of each factor through the runs.

\begin{tabular}{|c|c|c|c|c|}
\hline \multirow{2}{*}{ SN } & \multirow{2}{*}{$\begin{array}{c}\text { Glass Fiber Content } \\
(\%)\end{array}$} & \multirow{2}{*}{$\begin{array}{l}\text { Fiber Orientation } \\
\left(^{(}\right)\end{array}$} & \multicolumn{2}{|c|}{ Tensile Strength } \\
\hline & & & Mean (MPa) & S/N Ratio (dB) \\
\hline 1 & 10 & 0 & 17.49 & 24.8558 \\
\hline 2 & 10 & 15 & 16.91 & 24.5629 \\
\hline 3 & 10 & 30 & 15.19 & 23.6312 \\
\hline 4 & 10 & 45 & 14.54 & 23.2513 \\
\hline 5 & 10 & 60 & 14.39 & 23.1612 \\
\hline 6 & 20 & 0 & 49.70 & 33.9271 \\
\hline 7 & 20 & 15 & 59.65 & 35.5122 \\
\hline 8 & 20 & 30 & 70.96 & 37.0203 \\
\hline 9 & 20 & 45 & 78.04 & 37.8463 \\
\hline 10 & 20 & 60 & 72.81 & 37.2438 \\
\hline 11 & 30 & 0 & 51.09 & 34.1667 \\
\hline 12 & 30 & 15 & 56.87 & 35.0977 \\
\hline 13 & 30 & 30 & 61.03 & 35.7109 \\
\hline 14 & 30 & 45 & 64.70 & 36.2181 \\
\hline 15 & 30 & 60 & 62.91 & 35.9744 \\
\hline 16 & 40 & 0 & 59.28 & 35.4582 \\
\hline 17 & 40 & 15 & 80.25 & 38.0889 \\
\hline 18 & 40 & 30 & 106.30 & 40.5307 \\
\hline 19 & 40 & 45 & 125.74 & 41.9895 \\
\hline 20 & 40 & 60 & 116.96 & 41.3607 \\
\hline
\end{tabular}




\begin{tabular}{lcccc}
\hline 21 & 50 & 0 & 78.49 & 37.8963 \\
22 & 50 & 15 & 129.61 & 42.2528 \\
23 & 50 & 30 & 183.25 & 45.2609 \\
24 & 50 & 45 & 209.65 & 46.4299 \\
25 & 50 & 60 & 185.70 & 45.3762 \\
& & Mean & 79.26 & 35.712954 \\
\hline
\end{tabular}

Table 4: Response table for means and S/N ratio

\begin{tabular}{ccccc}
\hline \multirow{2}{*}{ SN } & \multicolumn{2}{c}{ Glass Fiber Content } & \multicolumn{2}{c}{ Fiber Orientation } \\
\cline { 2 - 5 } & Mean (MPa) & S/N Ratio (dB) & Mean (MPa) & S/N Ratio (dB) \\
\hline 1 & 15.7 & 23.89 & 51.21 & 33.26 \\
2 & 66.23 & 36.31 & 68.66 & 35.1 \\
3 & 59.32 & 35.43 & 87.35 & 36.43 \\
4 & 97.71 & 39.49 & 98.53 & 37.15 \\
5 & 157.34 & 43.44 & 90.55 & 36.62 \\
Delta & 141.64 & 19.55 & 47.32 & 3.89 \\
Rank & 1 & 1 & 2 & 2 \\
\hline
\end{tabular}

In Table 4, it is observed that the glass fiber content has the highest ranking, implying its ability to influence the tensile strength of the glass fiber reinforced epoxy composites more than the fiber orientation. Figure 1 and Figure 2 show the variation of tensile strength with change in glass fiber content and fiber orientation respectively. The rise in tensile strength of the composite from glass fiber composition of $10 \%$ is due to the ease and efficient transfer of stress from the matrix to the fiber due to the increase in fiber strength. The increase in tensile strength with the increase in fiber content is a logical trend that has been observed by other studies (Pothan et al., 1997; Khan et al., 2021; Sapuan et al., 2020).

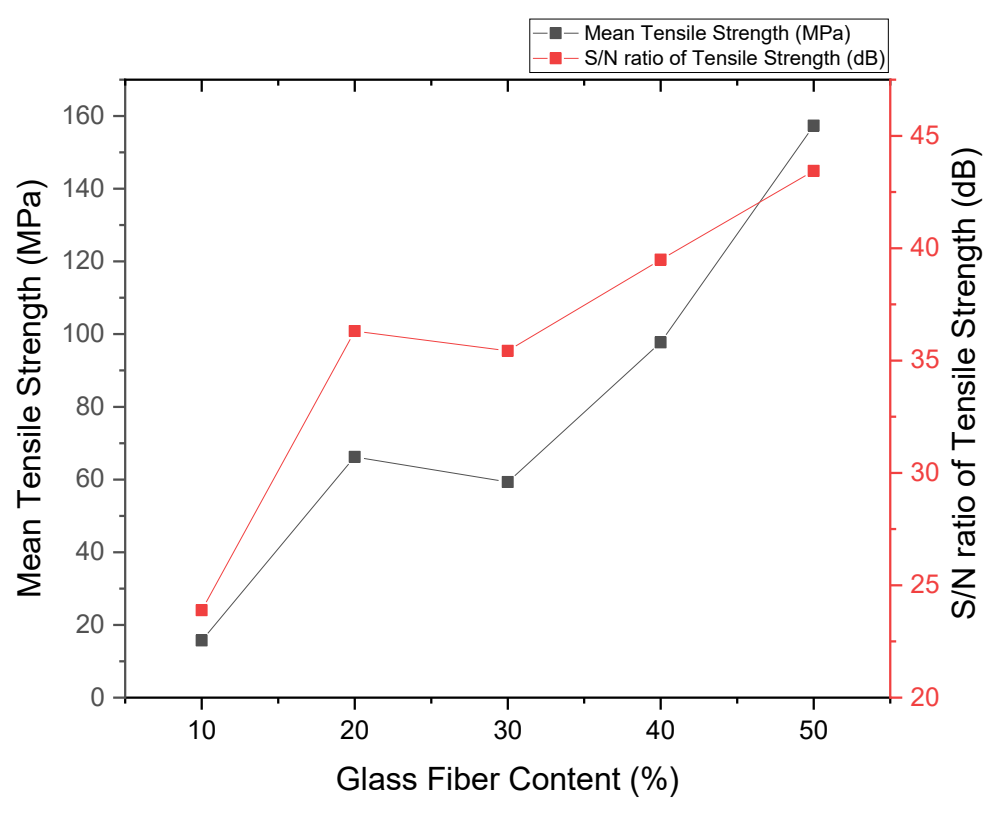


Figure 1: Variation tensile strength with glass fiber content

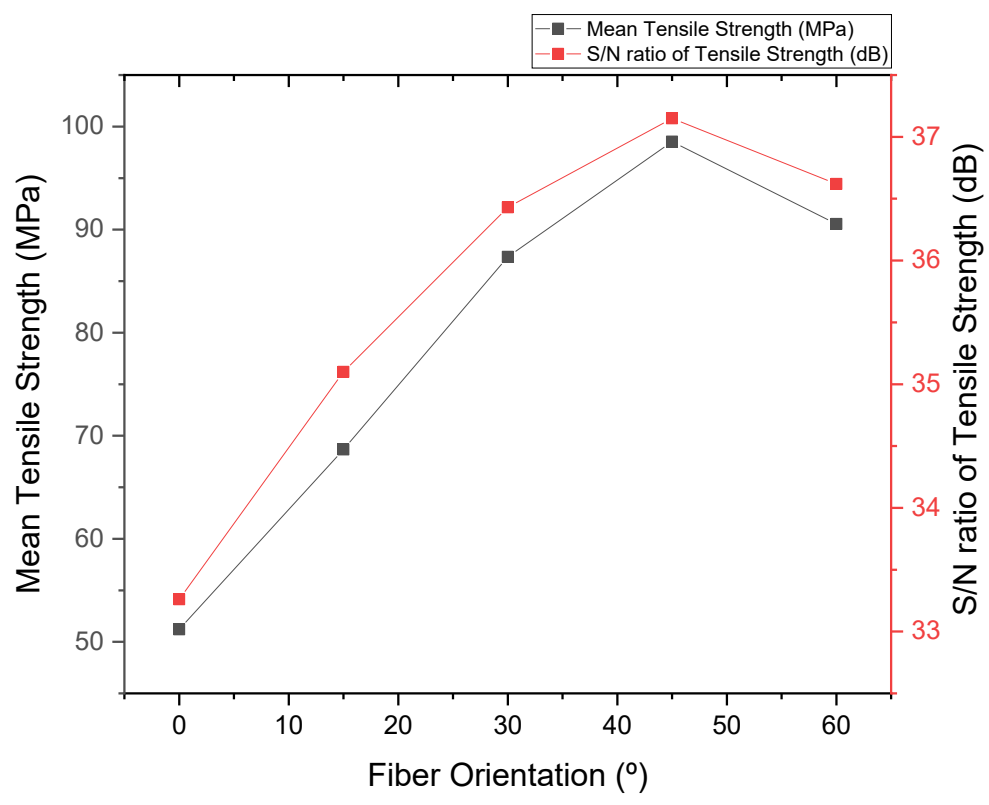

Figure 2: Variation tensile strength on fiber orientation

Figure 2 shows a corresponding increase in tensile strength of the glass fiber reinforced epoxy composite with an increase in fiber orientation (angle). The increase in fiber orientation is due to the best possible alignment of the fiber with the direction of stress. The best tensile strength was observed at a fiber orientation of $45^{\circ}$. This agrees with the work of Kumar et al., (2020) in which the best fiber orientation was observed to be at $\pm 45^{\circ}$. Pressure build-up within pipelines acts at direction transverse to the pipe's main axis. The drop in tensile strength of the material beyond the $45^{\circ}$ is indicative of the reverse in alignment between the fiber and the tensile force.

\section{Analysis of Variance}

An analysis of variance at a confidence level of $0.05(95 \%)$ was used to determine the significance of each of the development factors (glass fiber content and fiber orientation) on the tensile strength of the composite. The analysis of variance for mean and $\mathrm{S} / \mathrm{N}$ ratio is presented in Table 5 and Table 6.

Table 5: Analysis of variance for means

\begin{tabular}{cccccccc}
\hline $\begin{array}{c}\text { Factor } \\
\text { (Variable } \\
\text { Parameter) }\end{array}$ & DF & Seq SS & Adj SS & Adj MS & F & P & $\begin{array}{c}\text { Percentage } \\
\text { Contribution } \\
(\%)\end{array}$ \\
\hline $\begin{array}{c}\text { Glass fiber } \\
\text { content (\%) } \\
\text { (A) }\end{array}$ & 4 & 55217 & 55217 & 13804.3 & 29.29 & 0.000 & 78.8 \\
$\begin{array}{c}\text { Fiber } \\
\text { orientation }\left({ }^{\circ}\right)\end{array}$ & 4 & 7318 & 7318 & 1829.5 & 3.88 & 0.022 & 10.44 \\
$\begin{array}{c}\text { (B) } \\
\text { Residual Error } \\
\text { Total }\end{array}$ & 16 & 7540 & 7540 & 471.2 & & & 10.76 \\
\hline
\end{tabular}

Table 6: Analysis of variance for $\mathrm{S} / \mathrm{N}$ ratio

\begin{tabular}{cccccccc}
\hline $\begin{array}{c}\text { Factor } \\
\text { Variable }\end{array}$ & DF & Seq SS & Adj SS & Adj MS & F & P & $\begin{array}{c}\text { Percentage } \\
\text { Contribution }\end{array}$ \\
\hline
\end{tabular}




\begin{tabular}{|c|c|c|c|c|c|c|c|}
\hline Parameter) & & & & & & & $(\%)$ \\
\hline $\begin{array}{l}\text { Glass fiber } \\
\text { content (\%) } \\
\text { (A) }\end{array}$ & 4 & 1070.74 & 1070.74 & 267.685 & 98.66 & 0.000 & 92.06 \\
\hline $\begin{array}{c}\text { Fiber } \\
\text { orientation }\left({ }^{\circ}\right) \\
\text { (B) }\end{array}$ & 4 & 48.93 & 48.93 & 12.232 & 4.51 & 0.013 & 4.21 \\
\hline Residual Error & 16 & 43.41 & 43.41 & 2.713 & & & 3.73 \\
\hline Total & 24 & 1163.08 & & & & & 100 \\
\hline
\end{tabular}

Table 5 and Table 6 show that the glass fiber content had a significant effect on the tensile strength of the angularly oriented glass fiber reinforced epoxy composite with a P-value of 0.00 at means and $\mathrm{S} / \mathrm{N}$ ratio which is less than 0.05. Also, the glass fiber content in the polymer composite was observed to have a percentage contribution of $78.8 \%$ at means and $92.06 \%$ at the $\mathrm{S} / \mathrm{N}$ ratio. This implies that the glass fiber content has a $92.06 \%$ efficiency in affecting (increasing or decreasing) the tensile strength of the material.

Also, it was observed that the fiber orientation was significant with a P-value at a confidence level of $95 \%$ was of 0.022 at means and 0.013 at $\mathrm{S} / \mathrm{N}$ ratio. This significance was also observed at a fiber orientation percentage contribution of $10.44 \%$ at means and $4.21 \%$ at the $\mathrm{S} / \mathrm{N}$ ratio. This implies that the fiber orientation has significant potential in affecting the tensile strength of a glass fiber reinforced epoxy composite.

\section{Optimal Combination}

From Figure 1 and Figure 2, the best tensile strength is observed at a fiber content of 50\% (A5), and fiber orientation of $45^{\circ}$ (B4). This implies that in other to obtain the best tensile strength, the material must be developed with a glass fiber content of $50 \%$ oriented at $45^{\circ}$ to the stress direction. The predicted optimum tensile strength is calculated from Equation 2:

$$
T_{\text {opt }}=T_{m}+\sum_{i=1}^{x}\left(T_{i}-T_{m}\right)
$$

Where $T_{\text {opt }}$ is the optimal tensile strength, $T_{m}$ is the mean of means obtained from Table 3 , and $T_{i}$ is the maximum tensile strength at each factor (obtained from Table 4). Therefore, the optimum tensile strength is 176.61MPa. In other to confirm the suitability of Equation 1 for predicting the optimal tensile strength, a confirmation test is carried out with the optimum combination. The tensile strength at an optimum combination (fiberglass at $50 \%$ and $45^{\circ}$ ) was observed to be $209.65 \mathrm{MPa}$. Comparison is made between the predicted tensile strength of $176.61 \mathrm{MPa}$ with an experimental tensile strength of 209.65MPa. The percentage error is calculated using equation (3).

$$
\text { Percentage error }=\frac{\text { Confirmation Tensile Strength-Predicted Tensile Strength }}{\text { Predicted Tensile Strength }}
$$

Therefore, the percentage error between the predicted and observed optimal strength is $18.7 \%$. This implies that the Taguchi design of experiment is $82 \%$ efficient in the determination of the optimal tensile strength of the angularly oriented glass fiber reinforced epoxy composite.

\section{Regression Analysis}

The tensile strength of the glass fiber reinforced epoxy composite was modeled with respect to the glass fiber content and fiber orientation using the regression analysis. The model is presented in equation 4.

Tensile strength $=-36.88+A 3.15+B 0.724$

The model R-Square value was 0.791 which shows a high degree of accuracy. This implies that the model has a $79.1 \%$ chance of predicting the tensile strength of the developed composite at various combinations of fiber content and fiber orientation. Figure 3 shows a comparison between the predicted (modeled) tensile strength and the experimented value. 


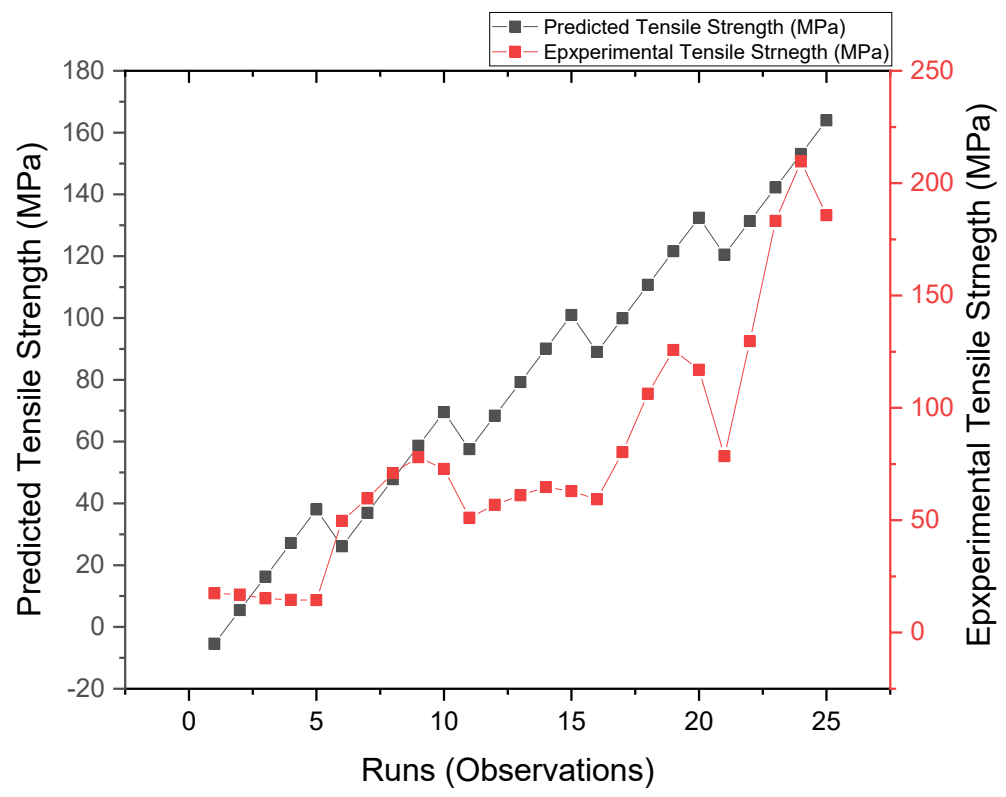

Figure 3: Comparison between the modeled and experimented tensile strength of the composite

\section{Conclusion}

In this study, parameters for the development of glass fiber reinforced epoxy composite was optimized using the robust Taguchi experimental design, and the effect of fiber orientation and fiber content on the tensile strength of the developed composite was studied using statistical analysis, and the following conclusions were made:

- Glass fiber at $50 \%$ fiber content and $45^{\circ}$ fiber orientation produced the optimum tensile strength of $209.65 \mathrm{MPa}$.

- The fiber content and fiber orientation were observed to have a significant effect on the tensile strength of the materials.

This study paves the way for the study on multi-angular orientation stacked fiberglass reinforced epoxy composites.

\section{Declaration}

Funding: This research did not receive any funding

Conflicts of interest/Competing interests: The author declares no conflict of interest

Availability of data and material: Not applicable

Code availability: Not applicable

Ethics approval: Not applicable

Consent to participate: Not applicable

Consent for publication: Not applicable 


\section{References}

Aramide, F. O., Atanda, P. O., \& Olorunniwo, O. O. (2012). Mechanical properties of a polyester fibre glass composite. International Journal of Composite Materials, 2(6), 147-151.

Batu, T., \& Lemu, H. G. (2020). Investigation of mechanical properties of false banana/glass fiber reinforced hybrid composite materials. Results in Materials, 8, 100152.

Elkazaz, E., Crosby, W. A., Ollick, A. M., \& Elhadary, M. (2020). Effect of fiber volume fraction on the mechanical properties of randomly oriented glass fiber reinforced polyurethane elastomer with crosshead speeds. Alexandria Engineering Journal, 59(1), 209-216.

Joseph, S., Sreekala, M. S., Oommen, Z., Koshy, P., \& Thomas, S. (2002). A comparison of the mechanical properties of phenol formaldehyde composites reinforced with banana fibres and glass fibres. Composites Science and Technology, 62(14), 1857-1868.

Khan, Z. I., Arsad, A., Mohamad, Z., Habib, U., \& Zaini, M. A. A. (2021). Comparative study on the enhancement of thermo-mechanical properties of carbon fiber and glass fiber reinforced epoxy composites. Materials Today: Proceedings, 39, 956-958.

Kumar, N., Avinash, P., Singh, A., \& Debnath, K. (2020). Effect of Fiber Orientation on the Tensile and Wear Properties of Flax Fiber-Reinforced Composites. In Advances in Mechanical Engineering (pp. 505-513). Springer, Singapore.

Mostafa, N. H. (2019). Tensile and fatigue properties of Jute-Glass hybrid fibre reinforced epoxy composites. Materials Research Express, 6(8), 085102.

Nair, K. M., Diwan, S. M., \& Thomas, S. (1996). Tensile properties of short sisal fiber reinforced polystyrene composites. Journal of applied polymer science, 60(9), 1483-1497.

Negawo, T. A., Polat, Y., Akgul, Y., Kilic, A., \& Jawaid, M. (2021). Mechanical and dynamic mechanical thermal properties of ensete fiber/woven glass fiber fabric hybrid composites. Composite Structures, 259, 113221.

Pothan, L. A., Thomas, S., \& Neelakantan, N. R. (1997). Short Banana Fiber Reinforced Polyester Composites: Mechanical, Failure and Aging Characteristics. Journal of Reinforced Plastics and Composites, 16(8), 744765. https://doi.org/10.1177/073168449701600806

Sapuan, S. M., Aulia, H. S., Ilyas, R. A., Atiqah, A., Dele-Afolabi, T. T., Nurazzi, M. N., ... \& Atikah, M. S. N. (2020). Mechanical properties of longitudinal basalt/woven-glass-fiber-reinforced unsaturated polyesterresin hybrid composites. Polymers, 12(10), 2211.

Sari, N. H., Pruncu, C. I., Sapuan, S. M., Ilyas, R. A., Catur, A. D., Suteja, S., ... \& Pullen, G. (2020). The effect of water immersion and fibre content on properties of corn husk fibres reinforced thermoset polyester composite. Polymer Testing, 91, 106751. 